\title{
Atividade antimicrobiana do óleo essencial de rizomas de açafrão (Curcuma longa L.) e gengibre (Zingiber officinale Roscoe) frente a salmonelas entéricas isoladas de frango resfriado
}

\author{
MAJOLO, C. ${ }^{1,2^{*}}$; NASCIMENTO, V.P. ${ }^{2}$; CHAGAS, E.C. ${ }^{1 ;}$ CHAVES, F.C.M. ${ }^{1}$ \\ ${ }^{1 *}$ EMBRAPA Amazônia Ocidental, AM 10, Km 29, zona rural, Caixa Postal 319, Manaus/AM, 69010-970, Brasil. \\ E-mail: claudia.majolo@embrapa.br; ${ }^{2}$ Programa de Pós-Graduação em Ciências Veterinárias, Universidade \\ Federal do Rio Grande do Sul, Av. Bento Gonçalves 9090, Porto Alegre, RS 91540-000, Brasil
}

\begin{abstract}
RESUMO: Objetivou-se com este trabalho identificar, quantificar os constituintes, e avaliar a atividade antibacteriana dos óleos essenciais extraídos de rizomas de açafrão (Curcuma longa L.) e gengibre (Zingiber officinale Roscoe) cultivados nas condições de Manaus/AM frente a 14 salmonelas entéricas isoladas de frango resfriado. A extração dos óleos essenciais foi realizada utilizando-se aparelho tipo Clevenger e a composição determinada por Cromatografia Gasosa acoplada a Espectrometria de Massas (CG-MS). A atividade antibacteriana foi realizada com o emprego de técnica de microdiluição em caldo. O óleo essencial de gengibre se mostrou expressivamente mais eficiente do que o óleo de açafrão, tanto em termos de ação bacteriostática (concentração inibitória mínima de 2500 a $5000 \mu \mathrm{g} \cdot \mathrm{mL}^{-1}$ ) quanto bactericida (concentração bactericida mínima de 5000 a $10000 \mu \mathrm{g} . \mathrm{mL}^{-1}$ ) observando-se variação apenas em duas as amostras em termos de resistência a ação bactericida deste óleo. Assim, o óleo essencial de gengibre, representa uma alternativa para o controle de Salmonella enterica, entretanto, demais estudos abordando o sinergismo com alimentos são indicados.
\end{abstract}

Palavras-chave: plantas medicinais, antimicrobianos naturais, sorovares de Salmonella.

ABSTRACT: Antimicrobial activity of essential oil from Curcuma longa and Zingiber officinale rhizomes against enteric Salmonella isolated from chicken. The objective of this work was to identify, quantify constituents and evaluate the antibacterial activity of essential oils from rhizomes of turmeric (Curcuma longa L.) and ginger (Zingiber officinale Roscoe) grown under conditions of Manaus/AM front of enteric salmonella isolated from chilled poultry. The extraction of essential oils was performed using the Clevenger type apparatus and composition determined by Gas Chromatography coupled to Mass Spectrometry (GC-MS). The antibacterial activity was performed with the use of microdilution broth. The essential oil of ginger proved significantly more efficient than tumeric oil, both in terms of bacteriostatic action (minimum

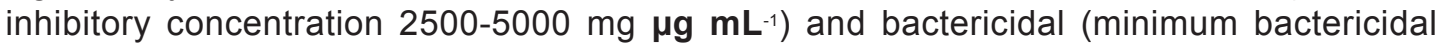
concentration $5000-10000 \mathrm{mg} \boldsymbol{\mu g ~ m L}^{-1}$ ) observing changes in only two samples in terms of resistance to bactericidal activity of this oil. Thus, the essential oil of ginger, is an alternative for the control of Salmonella enterica, however, other studies addressing the synergism with food are indicated

Keywords: medicinal plants, natural antimicrobials, Salmonella serovars.

\section{INTRODUÇÃO}

As enfermidades transmitidas por alimentos (ETA's) constituem-se uma preocupação para a área da saúde pública. Em países desenvolvidos, que possuem um bom sistema de vigilância epidemiológica, tem-se observado aumento significativo na incidência das mesmas (MMRW, 2004; 2008), sendo a Salmonella, um dos patógenos mais envolvidos em casos destas ETA's (WHO, 2010).

Diversos estudos epidemiológicos indicam os alimentos de origem animal, como um dos maiores veículos na transmissão de enfermidades causadas por Salmonella, tendo a carne de frango, particular importância na transmissão deste

Recebido para publicação em 07/10/2013

Aceito para publicação em 11/03/2014

10.1590/1983-084X/13_109

Rev. Bras. PI. Med., Campinas, v.16, n.3, p.505-512, 2014. 
patógeno (Whyte et al., 2002; Cretikos et al., 2008; Scallan et al., 2011).

Durante os últimos anos, o limite de infecções por Salmonella foi excedido drasticamente e este micro-organismo tornou-se um desafio na indústria de alimentos, devido a sua distribuição generalizada em todo o mundo, não sendo apenas responsáveis por infecções leves a graves, mas também podendo causar infecções fatais (Bajpal et al., 2012)

O aumento de infecções alimentares provocadas pelos sorotipos de Salmonella ocorre principalmente devido ao desenvolvimento de novas características específicas, tornando-as capazes de se adaptar em qualquer condição ambiental. Salmonelas resistentes à antibióticos comerciais tem emergido como uma grande preocupação de saúde para os consumidores revelando que a infecção por salmonelas resistentes a antibióticos tem desempenhado um papel vital para o aumento da taxa de ETA's (Bajpal et al., 2012).

Segundo Haida et al. (2007), a procura de novos antimicrobianos a partir de espécies vegetais, tem se mostrado bastante expressiva nos últimos anos, visando solucionar os problemas da resistência microbiana a antibióticos atualmente utilizados.

Originalmente utilizadas para alterar ou melhorar o sabor dos alimentos, as ervas e especiarias possuem metabólitos secundários, como os óleos essenciais, que desempenham papel protetor de plantas contra agentes infecciosos como bactérias (Bakkalil et al., 2008), sendo consideradas importantes substâncias bioativas (Shao et al., 2011).

A busca de garantias para a segurança alimentar e, concomitantemente, o atendimento às demandas para conservação e qualidade, vem impulsionando a pesquisa para o desenvolvimento de métodos alternativos na conservação de alimentos. Essas crescentes demandas abrem novas perspectivas para o uso de conservantes naturais, dentre eles, os derivados de plantas (Tiwaril et al., 2009). Dentre estes derivados, os óleos essenciais de Curcuma longa L. e Zingiber officinale Roscoe tem sido estudados para este propósito.

Curcuma longa L., conhecida popularmente como açafrão ou açafrão da Índia, é uma planta originária da Índia e cultivada em todo mundo tropical (Lorenzi \& Matos, 2002).

Da sua raiz seca e moída se extrai o pó, utilizado na culinária como condimento ou corante de cor amarela e brilhante, e no preparo de medicamentos. Em sua composição química, o principal constituinte é a curcumina, possuindo também óleo essencial de excelente qualidade técnica e organoléptica, que, juntos, possibilitam estender sua utilização também aos mercados de perfumaria e têxtil (Cecílio Filho, 2000).

Estudos demonstram que o óleo essencial de Curcuma longa L. apresenta poder antimicrobiano em potencial contra diferentes patógenos alimentares incluindo diferentes sorovares de Salmonella (Franco et al., 2007; Péret-Almeida et al., 2008; Rattanachaikunsopon \& Phumkhachorn, 2010).

Zingiber officinale Roscoe conhecido como gengibre, possui rizoma ramificado, de cheiro e sabor picante, agradável (Lorenzi \& Matos, 2002), apresenta forte atividade antimicrobiana sendo amplamente utilizada como especiaria da culinária além de ser bem conhecido na medicina tradicional (Yadav et al., 2012).

Estudos realizados com seus óleos essenciais e extratos de gengibre frente a diversos patógenos alimentares verificaram excelente atividade antimicrobiana, incluindo atividade contra diferentes sorovares de Salmonella (Sa-Nguanpuag, 2011; Yousufil, 2012; Ahmed, 2012).

O presente estudo foi realizado com o objetivo de identificar e quantificar os constituintes dos óleos essenciais de Curcuma longa L. e Zingiber officinale Roscoe cultivados nas condições edafoclimáticas de Manaus - AM e avaliar sua atividade antimicrobiana frente a 14 salmonelas isoladas de amostras de frango resfriado.

\section{MATERIAL E MÉTODO}

\section{Micro-organismos}

Foram utilizados 14 cepas de Salmonella enterica, isolados de frango resfriado, incluindo os sorovares: Schwarzengrund (2), Heidenberg (1), Mbandaka (3), Enteritidis (2), Typhimurium (1), Agona (1) e 4 isolados sem identificação possível, apenas confirmando a subespécie enterica.

\section{Óleos essenciais}

Os óleos essenciais avaliados foram obtidos a partir rizomas de Curcuma longa L. (açafrão) e de Zingiber officinale Roscoe (gengibre) cultivados no Setor de Plantas Medicinais da Embrapa Amazônia Ocidental, município de Manaus/AM, situada a $03^{\circ}$ $06^{\prime} 23,04$ 'S e $60^{\circ} 01^{\prime} 35,14$ 'W. A altitude média é de 50 metros e temperatura média de $25,6^{\circ} \mathrm{C}$, com precipitação média de $2.200 \mathrm{~mm}$ anual. O clima é do tipo "Afi", segundo classificação de Köppen (RIBEIRO, 1976).

Após oito meses de cultivo (do plantio a colheita) quando as folhas estavam amareladas, acamadas (agosto de 2012) foi feita a colheita dos rizomas de ambas as espécies, sendo em seguida colocados para secar à temperatura ambiente, à 
sombra, em galpão telado. Decorridos cinco dias foram peneirados para retirada de resto de solo e em seguida foram encaminhados para o Laboratório de Plantas Medicinais e Fitoquímica, também da Embrapa. Os rizomas foram cortados em fatias bem finas para facilitar a extração de óleo essencial que foi realizada através de hidrodestilação utilizando o aparelho do tipo Clevenger. O óleo foi separado da fase aquosa e seco com Sulfato de Sódio (CRQ, Diadema, São Paulo, Brasil), filtrado e armazenado em recipientes de vidro opaco, mantendo-se à temperatura de $8{ }^{\circ} \mathrm{C}$ até $\mathrm{o}$ momento da sua utilização.

Para avaliação da composição química dos óleos essenciais das espécies supracitadas, foi utilizado um cromatógrafo a gás Agilent (Palo Alto, USA) $7890 \mathrm{~A}$ equipado com coluna capilar HP-5 (5\%-difenil-95\%-dimetilsilicone, 30m X 0,32mm $X 0,25 \mu \mathrm{m})$. A programação de temperatura do forno foi de 60 a $240{ }^{\circ} \mathrm{C}$, a $3{ }^{\circ} \mathrm{C} / \mathrm{min}$, usando-se hidrogênio como gás carreador $\left(1,5 \mathrm{~mL}\right.$. $\left.\mathrm{min}^{-1}\right)$. Foi injetado 1,0 $\mu \mathrm{L}$ de uma solução $1 \%$ do óleo essencial em Diclorometano (Merck Millipore, Darmstadt, Germany) no modo com divisão de fluxo (1:100; injetor a $250{ }^{\circ} \mathrm{C}$ ). Os espectros de massa foram obtidos em um sistema Agilent $5973 \mathrm{~N}$ operado no modo impacto de elétrons (EIMS) a $70 \mathrm{eV}$, acoplado a um cromatógrafo Agilent 6890 equipado com coluna HP-5 MS (5\%-difenil-95\%-dimetilsilicone, $30 \mathrm{~m} \times 0,25 \mathrm{~mm} \times 0,25 \mathrm{~mm}$ ), usando o mesmo procedimento de injeção e programa de temperatura como descrito acima. $O$ hélio foi o gás carreador $(1,0$ $\left.\mathrm{mL} . \mathrm{min}^{-1}\right)$. Os índices de retenção foram calculados a partir dos tempos de retenção dos componentes dos óleos e aqueles de uma série de n-alcanos $\left(\mathrm{C}_{7}{ }^{-}\right.$ $\mathrm{C}_{26}$ ). A identificação dos constituintes foi realizada por comparação entre os espectros de massa obtidos e os dados de biblioteca espectral (Wiley $6^{\text {th }}$ ed.), e através do índice de retenção calculado e comparado com valores publicados (Adams, 2007).

\section{Determinação da Concentração Inibitória Mínima (CIM) e Concentração Bactericida Mínima (CBM)}

A atividade antimicrobiana dos óleos essenciais de açafrão e gengibre foi determinada pelo método de microdiluição em caldo utilizando placas contendo 96 poços, conforme NCCLS (M7-A6) (NCCLS, 2003), sendo determinadas a CIM e a CBM. Em cada placa foram aplicados os óleos essenciais nas concentrações testadas, o antimicrobiano Cloranfenicol (Flucka BioChemika, St. Gallen, Switzerland) e o diluente Dimetilsulfóxido (DMSO) (Sigma, St. Louis, Missouri, USA), todos em triplicata. Também foram feitos controles negativos (meio sem adição de inóculo) e controles positivos (meio com adição de inóculo).
Para o óleo essencial de gengibre, pesouse $0,2 \mathrm{~g}$ de óleo em $1 \mathrm{~mL}$ de DMSO. Desta forma foi obtida uma solução de $200.000 \mu \mathrm{g} \cdot \mathrm{mL}^{-1}$ (solução estoque). Para o óleo de açafrão, a quantidade de óleo para preparo da solução estoque foi aumentada proporcionalmente em função da observação de não atividade nas mesmas condições que o gengibre.

O padrão de antibiótico utilizado para verificação da atividade antimicrobiana foi o cloranfenicol 0,2 $\mu \mathrm{g} \cdot \mathrm{mL}^{-1}$.

Inicialmente foram transferidas alíquotas de $200 \mu \mathrm{L}$ do inóculo padronizado (108 unidades formadoras de colônia (UFC) $\mathrm{mL}^{-1}$ ) a tubos de ensaio contendo $10 \mathrm{~mL}$ de Tryptone Soya Broth (TSB) (Himedia, Mumbai, India). Para o óleo essencial utilizou-se o TSB com $1 \%$ do surfactante Tween 80 (Vetec, Rio de Janeiro, Brazil).

Para todos os poços da placa foram adicionados $100 \mu \mathrm{L}$ do meio acrescido de inoculo com exceção da última linha (controle do meio).

As primeiras colunas foram destinadas aos óleos essenciais e as demais ao cloranfenicol e ao meio acrescido do diluente DMSO.

Para o óleo essencial de gengibre foi efetuada uma diluição da solução estoque, onde foi adicionado $1 \mathrm{~mL}$ da solução estoque em $4 \mathrm{~mL}$ de TSB contendo $1 \%$ do surfactante Tween 80 , resultando dessa forma em uma solução com concentração de $40.000 \mu \mathrm{g} \cdot \mathrm{mL}^{-1}$. Desta solução foram retirados $100 \mu \mathrm{L}$ e adicionados em três poços da primeira linha; da mesma forma, foram aplicados $100 \mu \mathrm{L}$ do antimicrobiano cloranfenicol e DMSO diluído em TSB (controle do diluente), obtendo-se $\operatorname{assim} 200 \mu \mathrm{L}$ nos poços da linha $A$.

As diluições foram realizadas homogeneizando-se os primeiros poços com as amostras, transferindo $100 \mu \mathrm{L}$ para os próximos poços, e assim, sucessivamente, até a antepenúltima linha, obtendo-se as concentrações finais de 20000 , $10000,5000,2500,1250$ e $625 \mu \mathrm{g} \cdot \mathrm{mL}^{-1}$ para o óleo essencial de gengibre, 320000, 160000, 80000, 40000,20000 e $10000 \mu \mathrm{g} \cdot \mathrm{mL}^{-1}$ para o óleo essencial de açafrão e de 0,1, 0,05, 0,025, 0,0125, 0,00625 e $0,003125 \mu \mathrm{g} \cdot \mathrm{mL}^{-1}$ para o cloranfenicol.

Logo após a micropipetagem, as placas foram fechadas e incubadas a $35^{\circ} \mathrm{C}+/-1^{\circ} \mathrm{C}$ por 24 horas.

Após o tempo de incubação, realizou-se a leitura das placas. A confirmação de crescimento bacteriano foi representada pelo poço turvo e a ausência de crescimento foi representada pelo poço límpido. O primeiro poço onde não se observou crescimento (de menor concentração) correspondeu ao valor da concentração inibitória mínima (CIM).

A confirmação de crescimentos nos poços foi realizada por meio da aplicação da solução aquosa estéril de Cloreto de Trifeniltetrazólio 0,5\% 
(TTC) (Nuclear-CAQ, Diadema, SP, Brazil), revelada pelo aparecimento de uma cloração avermelhada.

Para determinação da CBM dos óleos essenciais foram realizadas semeaduras em placas de Tryptone Soya Agar (TSA) (Himedia, Mumbai, India), de todos os poços onde não havia revelação de crescimento bacteriano. Essas placas foram incubadas a $35^{\circ} \mathrm{C}+/-1^{\circ} \mathrm{C}$ por 24 horas.

Após o período de incubação, observouse o crescimento bacteriano, registrando-se a menor concentração dos óleos essenciais que não evidenciaram crescimento em placas.

\section{Análise estatística}

Para a avaliação dos dados foi realizada a análise de variância e teste de médias pelo método de Duncan (nível de significância com $5 \%$ de probabilidade) para avaliar se os diferentes isolados de Salmonella enterica em estudo, apresentavam perfis de suscetibilidade semelhantes ou não, frente a determinado óleo essencial.
Os resultados da composição química dos óleos essenciais de Curcuma longa L. (açafrão) e Zingiber officinale Roscoe (gengibre) estão apresentados nas Tabelas 1 e 2 .

Para o óleo essencial de açafrão foram identificados 19 constituintes, o que representa cerca de $68,2 \%$ do óleo essencial, sendo os compostos majoritários: ar-tumerona $(17,9 \%)$, alfatumerona $(14,6 \%)$ e 1,8-cineol $(14,2 \%)$ (Tabela 1). No óleo essencial de gengibre foram identificados 20 constituintes, representando $98,3 \%$ do óleo essencial, sendo o geranial (23,9\%), neral $(17,2 \%)$, 1,8-cineol $(16,0 \%)$ e canfeno $(11,4 \%)$ os compostos majoritários (Tabela 2).

\section{Atividade antibacteriana}

A atividade antibacteriana dos óleos essenciais de açafrão e gengibre, obtidas por microdiluição em caldo, expressas como CIM e CBM estão descritas na Tabela 3.

\section{RESULTADO E DISCUSSÃO}

\section{Composição química dos óleos essenciais}

Tabela 1. Constituintes químicos do óleo essencial de Curcuma longa L. (açafrão).

\begin{tabular}{ccc}
\hline Composto & $\%$ & $I R$ \\
\hline a-pineno & 0,6 & 932 \\
Mirceno & 0,5 & 990 \\
a-felandreno & 8,5 & 1005 \\
d-3-careno & 0,3 & 1010 \\
p-cimeno & 2,1 & 1023 \\
Limoneno + silvestreno & 0,9 & 1027 \\
1,8-cineol & 14,2 & 1030 \\
y-terpineno & 0,4 & 1057 \\
Terpinoleno & 2,3 & 1087 \\
Terpinen-4-ol & 0,5 & 1175 \\
a-terpineol & 0,8 & 1189 \\
Ar-curcumeno & 0,5 & 1481 \\
$\alpha$-Zingibereno & 0,5 & 1494 \\
$\beta$-sesquifelandreno & 0,6 & 1522 \\
Ar-tumerol & 1,7 & 1578 \\
$\beta$-atlantol & 0,7 & 1607 \\
Ar-tumerona & 17,9 & 1667 \\
$\alpha$-tumerona & 14,6 & 1701 \\
6S,7R-bisaboleno & 0,6 & 1744
\end{tabular}

IR: índice de retenção

Rev. Bras. Pl. Med., Campinas, v.16, n.3, p.505-512, 2014. 
Tabela 2. Constituintes químicos do óleo essencial de Zingiber officinale Roscoe (gengibre)

\begin{tabular}{|c|c|c|}
\hline Composto & $\%$ & IR \\
\hline 2-heptanol & 1,0 & 932 \\
\hline a-Pineno & 2,9 & 990 \\
\hline Canfeno & 11,4 & 1005 \\
\hline$\beta$-pineno & 0,6 & 1010 \\
\hline 6-metil-5-hepten-2-ona & 1,2 & 1023 \\
\hline Mirceno & 1,8 & 1027 \\
\hline$\beta$-felandreno + silvestreno & 4,1 & 1030 \\
\hline 1,8-cineol & 16,0 & 1057 \\
\hline Linalol & 1,8 & 1087 \\
\hline Borneol & 4,4 & 1175 \\
\hline Terpinen-4-ol & 0,6 & 1189 \\
\hline a-terpineol & 2,9 & 1481 \\
\hline Citronelol & 1,0 & 1494 \\
\hline Neral & 17,2 & 1522 \\
\hline Geraniol & 1,9 & 1578 \\
\hline Geranial & 23,9 & 1607 \\
\hline Ar-curcumeno & 1,1 & 1667 \\
\hline a-zingibereno & 2,2 & 1701 \\
\hline$(E, E)$ - $\alpha$-farneseno & 1,2 & 1744 \\
\hline
\end{tabular}

IR: índice de retenção

Tabela 3. Suscetibilidade de sorovares de Salmonella enterica isoladas de frango frente aos óleos essenciais de Curcuma longa L. (açafrão) e Zingiber officinale Roscoe (gengibre)

\begin{tabular}{lcccc}
\hline & \multicolumn{2}{c}{ Açafrão } & \multicolumn{2}{c}{ Gengibre } \\
\hline $\mathrm{N}^{\circ}$ da amostra/sorovar & CIM & CBM & CIM & CBM \\
1 / Schwarzengrund & 160000 & $>320000$ & $5000^{\mathrm{a}}$ & $6666,7^{\mathrm{a}}$ \\
2 / Enteritidis & $>320000$ & $>320000$ & $5000^{\mathrm{a}}$ & $5000^{\mathrm{a}}$ \\
3 / Mbandaka & 80000 & $>320000$ & $5000^{\mathrm{a}}$ & $5000^{\mathrm{a}}$ \\
4 / enterica subs enterica & 160000 & 160000 & $5000^{\mathrm{a}}$ & $5000^{\mathrm{a}}$ \\
5 / Enteritidis & 80000 & $>320000$ & $5000^{\mathrm{a}}$ & $5000^{\mathrm{a}}$ \\
6 / enterica subs enterica & 320000 & $>320000$ & $5000^{\mathrm{a}}$ & $5000^{\mathrm{a}}$ \\
7 / Heidelberg & 320000 & $>320000$ & $5000^{\mathrm{a}}$ & $5000^{\mathrm{a}}$ \\
8 / enterica subs enterica & 320000 & 320000 & $5000^{\mathrm{a}}$ & $5000^{\mathrm{a}}$ \\
9 / enterica subs enterica & $>320000$ & $>320000$ & $2500^{\mathrm{b}}$ & $10000^{\mathrm{b}}$ \\
10 / Typhimurium & $>320000$ & $>320000$ & $5000^{\mathrm{a}}$ & $5000^{\mathrm{a}}$ \\
11 / Schwarzengrund & $>320000$ & $>320000$ & $5000^{\mathrm{a}}$ & $10000^{\mathrm{b}}$ \\
12 / Agona & $>320000$ & $>320000$ & $5000^{\mathrm{a}}$ & $5000^{\mathrm{a}}$ \\
13 / Mbandaka & $>320000$ & $>320000$ & $5000^{\mathrm{a}}$ & $5000^{\mathrm{a}}$ \\
14 / Mbandaka & $>320000$ & $>320000$ & $5000^{\mathrm{a}}$ & $5000^{\mathrm{a}}$ \\
\hline
\end{tabular}

CIM: concentração inibitória mínima

CBM: concentração bactericida mínima

Resultados da CIM e CBM expressos em $\mu \mathrm{g} \mathrm{mL}^{-1}$

As médias de cada coluna seguidas pela mesma letra não diferem entre si pelo teste de Duncan a $5 \%$ de probabilidade

Rev. Bras. PI. Med., Campinas, v.16, n.3, p.505-512, 2014. 
Não foi possível fazer a análise estatística dos resultados de CIMs e CBMs dos óleos essenciais de açafrão e gengibre, pois o óleo essencial de açafrão apresentou em sua maioria, valores indeterminados. Entretanto, verifica-se expressiva diferença quanto à atividade bactericida (CBM) e bacteriostática $(\mathrm{CIM})$, revelando a superioridade em termos de atividade do óleo essencial de gengibre.

Para o óleo de açafrão a variação da CIM foi de 80000 a $>320000 \mu \mathrm{g} \cdot \mathrm{mL}^{-1}$ e a CBM variou de 160000 a >320000 $\mu \mathrm{g} \cdot \mathrm{mL}^{-1}$ (Tabela 3). Independentemente do sorovar de Salmonella avaliado, a resistência ao óleo essencial de açafrão foi alta.

Para a atividade antibacteriana a menor concentração do óleo essencial de açafrão capaz de inibir $50 \%$ dos isolados (CIM 50\% e CBM $50 \%$ ) foi superior a $320000 \mu \mathrm{g} \cdot \mathrm{mL}^{-1}$, tornando a determinação inconclusiva, comprovando a fraca atividade deste óleo essencial, em termos de ação bacteriostática como bactericida.

Quanto à composição química, Gounder \& Lingamalle (2012) também encontraram ar-tumerona e a-tumerona como compostos majoritários em óleo de açafrão, porém, em maiores concentrações, $21,0 \%$ e $33,5 \%$ respectivamente.

Singh et al. (2011), encontraram artumerona e curlona como componentes majoritários do óleo essencial de açafrão, apresentando excelente atividade frente à Staphylococcus aureus, Pseudomonas aeruginosa, Candida albicans e Aspergilus niger. Os autores justificam a atividade em função da elevada concentração de ar-tumerona.

Nanasombat \& Lohasupthawee (2005) avaliando extrato etanólico de açafrão não observaram atividade antibacteriana frente a 20 diferentes sorovares de Salmonella enterica, resultado similar ao do presente trabalho.

Franco et al. (2007), avaliando a ação antibacteriana com discos impregnados e difusão em ágar do óleo essencial de açafrão, não constatou atividade frente à Salmonella Choleraesuis, sendo que o óleo apresentava como componente majoritário a tumerona $(28,67 \%)$, coincidindo com os resultados deste trabalho.

De Bona et al. (2012) avaliaram extrato de açafrão frente a 14 sorovares de Salmonella isolados de frango, sendo que a CIM para Salmonella MBandaka, Salmonella Heidelberg e Salmonella Lexington foi 100, 150 e $200 \mu \mathrm{g} \cdot \mathrm{mL}^{-1}$ respectivamente, entretanto, a determinação de composição química destes extratos não foi realizada.

Para o óleo essencial de gengibre a variação da CIM foi de 2500 a $5000 \mu \mathrm{g} \cdot \mathrm{mL}^{-1}$ e a CBM variou de 5000 a $10000 \mu \mathrm{g} \cdot \mathrm{mL}^{-1}$ (Tabela 3).

Dentre os sorovares avaliados as amostras que apresentaram resistência semelhante entre eles e maior em relação às demais foram: 11 (Salmonella Schwarzengrund), e 9 (sem identificação) $(p<0,05)$ (Tabela 3). A amostra 9 também apresentou menor CIM entre todas as amostras.

No que diz respeito à composição química do óleo essencial de gengibre resultados semelhantes a este trabalho foram relatados por Singh et al. (2008) onde o composto majoritário encontrado foi o geraniale. Mesomo et al. (2013), encontraram como compostos majoritários a-curcumeno, geranial e canfeno, e, avaliando halos de inibição frente a Salmonella typhimurium, encontraram atividade fraca a moderada

Sa-Nguanpuag et al. (2011) avaliaram a ação antimicrobiana de óleo essencial de gengibre obtido por duas formas: hidrodestilação e extração por solventes, sendo que para os sorovares de Salmonella avaliados, o óleo essencial obtido por hidrodestilação, apresentou melhor ação antimicrobiana (2,5 a 10 mg.L-1) enquanto que ao ser avaliada através de discos de difusão, os resultados foram muito inferiores ao obtido no presente trabalho.

De Bona et al. (2012), avaliaram extrato de gengibre frente a 14 sorovares de Salmonella isolados de frango, sendo que a CIM para Salmonella Montevedeo foi de $200 \mu \mathrm{g} \cdot \mathrm{mL}^{-1}$, não sendo observada a inibição de nenhum outro dos sorovares testados.

A composição química dos óleos testados foi variável com os dados relatados na literatura, o que pode ser explicado devido a influência de diversos fatores, tais como: ambiente, estádio de desenvolvimento ou idade da planta (Oliveira et al., 2012), podendo também justificar a variação de resultados de CIM e CBM relatados em comparação a outros estudos.

Trabalhos avaliando a ação de óleos essenciais de gengibre e de açafrão evidenciaram a ação antibacteriana mais efetiva frente a bactérias Gram-positivas (Sa-Nguenpuag, 2011; Ahmed, 2012; Shanoon, 2012). Sendo a Salmonella uma bactéria Gram-negativa, apresenta maior resistência do que outras espécies Gram-positivas (Preuss, 2005), podendo ser justificada pela dupla camada fosfolipídica, que protege a célula bacteriana de determinadas classes de compostos presentes nos óleos essenciais (Oussalah, 2007).

A falta de padronização das técnicas empregadas resulta em grandes variações nas CIM's e CBM's mesmo quando da utilização de óleos de composição similar.

Os resultados desta pesquisa permitiram evidenciar superioridade da atividade do óleo essencial de gengibre em comparação ao de açafrão frente a salmonelas entéricas isoladas de frango, bem como a variação de susceptibilidade 
dos diferentes sorovares confrontadas.

Sendo o gengibre uma especiaria amplamente utilizada no preparo de pratos a base de carne de frango, sugerem-se estudos adicionais abordando o sinergismo entre o óleo essencial desta espécie e a matriz alimentar em questão, bem como a avaliação em termos organolépticos para mensuração da aceitação por consumidores das doses consideradas efetivas.

\section{REFERÊNCIA}

ADAMS R. P. Identification of Essential Oil Components by Gas Chromatography / Quadrupole Mass Spectroscopy. 4th ed., Illinois: Allured Publishing Co, Carol Stream, 2007.

AHMED, S.A et al. Study the antibacterial activity of Zingiber officinale roots against some of pathogenic bacteria. Al-Mustansiriya Journal Science, v.23, n.3, p.63-70, 2012.

BAJPAL, V.K. et al. Control of Salmonella in foods by using essential oils: A review. Food Research International, v.45, p. 722-734, 2012.

BAKKALI, F. et al. Biological effects of essential oils - A review. Food Chemestry and Toxicology, v.46, p.446475, 2008.

CECÍLIO FILHO, A.B. et al. Cúrcuma: planta medicinal, condimentar e de outros usos potenciais. Ciência Rural, Santa Maria, v.30, n.1, p.171-75, 2000.

CRETIKOS, M. et al. Enteric disease outbreak reporting, New South Wales, Australia, 2000 to 2005. New South Wales Public Health Bullettin, v.19, n.1-2, p.3-7, 2008.

DE BONA, E.A.M. et al. Avaliação da atividade antimicrobiana de extratos vegetais frente a sorovares de Salmonella spp. de origem avícola. Revista Unopar Científica Ciências Biológicas e da Saúde, v.15, n.1, p.41-6, 2012.

FRANCO, A.L.P. et al. Avaliação da composição química e atividade antibacteriana dos óleos essenciais de Aloysia gratissima (Gillies \& Hook) Tronc. (Alfazema), Ocimum gratissimum L. (alfavaca-cravo) e Curcuma longa L. (açafrão). Revista Eletrônica de Farmácia, v.4, n.2, p.208-20, 2007.

GOUNDER, D.K.; LINGAMALLU, J. Comparison of chemical composition and antioxidant potential of volatile oil from fresh, dried and cured turmeric (Curcuma longa) rhizomes.Industrial Crops and Products, v.38, p.124-31, 2012.

HAIDA, K.S. et al. Avaliação in vitro da atividade antimicrobiana de oito espécies de plantas medicinais. Arquivos de ciências da saúde da UNIPAR, v.11, n.3, p.185-92, 2007.

LORENZI, H.; MATOS, F.J.A. Plantas medicinais no Brasil: nativas e exóticas. Nova Odessa SP: Instituto Plantarum, 2002, 512p.

MESOMO, M.C. et al. Supercritical CO2 extracts and essential oil of ginger (Zingiber officinale R.):Chemical composition and antibacterial activity. The Journal of Supercritical Fluids, v.80, p.44-49, 2013.

MORBIDITY AND MORTALITY WEEKLY REPORT
(MMWR). Preliminary FoodNet Data on the Incidence of Infection with Pathogens Transmitted Commonly Through Food - Selected Sites, United States, 2003. v.53, n.16, p.338-43, 2004.Disponível em: http://www. cdc.gov/mmwR/preview/mmwrhtml/mm 5316a2.htm. Acesso em: 24 jul. 2010.

MORBIDITY AND MORTALITY WEEKLY REPORT (MMWR). Preliminary FoodNet data on the incidence of infection with pathogens transmitted commonly through food - 10 states, 2007. Weekly, April 11, v.57, n.14, p.336-70, 2008. Disponível em: http://www. cdc.gov/mmwr/preview/mmwrhtml/mm5714a2.htm Acesso em: 24 jul. 2010.

NANASOMBAT, S.; LOHANSUTHAWEE, P. Antibacterial activity of crude ethanolic extracts and essential oils of species against salmonellae and other enterobacteria. King Mongkut's Institute of Technology Ladkrabang Science and Technology Journal, v.5, n.3, 2005.

NCCLS (National Committee for Clinical Laboratory Standards). Methods for dilution antimicrobial susceptibility tests for bacteria that grow aerobically Approved standard M7-A6, Wayne, Pa, USA, 2003.

OLIVEIRA, A.R.M.F. et al. Influência da idade da planta na produção de óleo essencial de alevante. Revista Ceres, v.59, n.2, p.241-45, 2012.

OUSSALAH, M. et al. Inhibitory effects of selected plant essential oils on the growth of four pathogenic bacteria: E. coli O157: H7, Salmonella Typhimurium, Staphylococcus aureus and Listeria monocytogenes. Food Control, v.18, p. 414-20, 2007.

PÉRET-ALMEIDA, L. et al. Atividade antimicrobiana in vitro do rizoma em pó, dos pigmentos curcuminóides e dos oleos essenciais da Curcuma longa L. Ciência e agrotecnologia, v.32, n.3, p.875-81, 2008.

PREUSS, H.G. et al. Minimum inhibitory concentrations of herbal essential oils and monolaurin for gram-positive and gram-negative bacteria. Molecular and Cellular Biochemestry, v.272, p.29-34, 2005.

RATTANACHAIKUNSOPON, P., PHUMKHACHORN, P. Antimicrobial activity of basil (Ocimum basilicum) oil against Salmonella Enteritidis in vitro and in food. Bioscience, Biotechnology, and Biochemistry, v.74, n.6, p.1200-1204, 2010.

RIBEIRO, M.N.G. Aspectos climáticos de Manaus. Acta Amazônica, Manaus, v. 6, p. 229-33, 1976.

SA-NGUANPUAG, K. et al. Ginger (Zingiber officinale) oil as an antimicrobial agent for minimally processed produce: a case study in shredded green papaya. International Journal of Agriculture \& Biology, v.13, n. 6, p.895-901, 2011.

SCALLAN, E. et al. Foodborne illness acquired in the United States-major pathogens. Emerging Infection Disease, 2011. Disponível em: http://www.cdc.gov/ EID/content/17/1/pdfs/09-1101p1.pdf. Acesso em: 31 jan. 2011.

SHAO, S. et al. Antimicrobials from plants - food preservation and shelf-life extension.in MOO-YOUNG, M.(Ed.). Comprehensive Biotechnology (Second Edition), University of Waterloo, Canada, 2011. v.4, p.645-58.

SHANOON, A.K. et al. Effects of Ginger (Zingiber officinale) Oil on Growth Performance and Microbial Population of Broiler Ross 308. International Journal 
of Poultry Science, v.11, n.9, p.589-593, 2012.

SINGH, G. et al. Chemistry, antioxidant and antimicrobial investigations on essential oil and oleoresins of Zingiber officinale. Food and Chemical Toxicology, v.46, p.295-302, 2008.

SINGH, S. et al. Chemical Composition of Tumeric Oil (Curcuma longa L cv Roma) and its Antimicrobial Activity against Eye Infection Pathogens. Journal of Essential Oil Research.v.23, n.6, p.11-18, 2011.

TIWARI, B. K. et al. Application of natural antimicrobials for food preservation: a review. Journal of Agricultural and Food Chemistry, v. 57, p.5987-6000, 2009.

WHYTE, P. et al. The prevalence and PCR detection of
Salmonella contamination in raw poultry. Veterinary Microbiology, v.89, p.53-60, 2002.

WORLD HEALTH ORGANIZATION (WHO). Zoonoses and veterinary public health. Disponível em: http:// www.who.int/zoonoses/vph/en/. Acesso em: 24 de jul. 2010.

YADAV, S. et al. Zingiber officinale Rosc.: A Monographic Review Research \& Reviews: Journal of Botany v.1, n.1, p.45-50, 2012.

YOUSUFI, M.K. To Study Antiacterial Activity of Allium Sativum, Zingiber officinale and Allium Cepa by KirbyBauer Method. IOSR Journal of Pharmacy and Biological Sciences. v.4, n.5, p.6-8, 2012. 